\title{
O ENSINO REMOTO EMERGENCIAL NA EDUCAÇÃO BÁSICA BRASILEIRA E PORTUGUESA: A PERSPECTIVA DOS DOCENTES
}

\author{
EMERGENCY REMOTE EDUCATION IN BRAZILIAN AND PORTUGUESE \\ SECONDARY EDUCATION: TEACHERS' PERSPECTIVE
}

\section{EDUCACIÓN REMOTA DE EMERGENCIA EN LA EDUCACIÓN SECUNDARIA BRASILEÑA Y PORTUGUESA: PERSPECTIVA DE LOS PROFESORES}

\author{
Sara Dias-Trindade ${ }^{1}$ \\ Joana Duarte Correia ${ }^{2}$ \\ Susana Henriques ${ }^{3}$
}

\begin{abstract}
Resumo: O impacto causado pela pandemia da COVID-19 levou ao encerramento de escolas por todo o mundo. Ministérios, governos estaduais, organismos públicos e privados viram-se repentinamente obrigados a converter todo o processo educativo para que milhões de estudantes continuassem os seus processos formativos a partir de suas casas. Do presencial transitou-se para o online, na forma de um ensino remoto de emergência, desafiando professores a repensarem metodologias e práticas pedagógicas, procurando desenvolver situações de aprendizagem em ambientes digitais. Este artigo, baseado numa análise exploratória, procura compreender como foi realizada essa transição do regime presencial para o regime digital na educação básica portuguesa e brasileira, nomeadamente no que diz respeito à preparação dos professores e das suas escolas. As respostas obtidas através da aplicação de um inquérito por questionário a 300 professores permitem um olhar sobre semelhanças e diferenças na abordagem à promoção de uma educação de qualidade em tempos de pandemia.
\end{abstract}

Palavras-chave: Educação básica. Ensino remoto emergencial. COVID-19. Competência digital docente.

\footnotetext{
${ }^{1}$ Universidade de Coimbra, Centro de Estudos Interdisciplinares do Século XX, Faculdade de Letras (DHEEAA). Coimbra, Portugal.

${ }^{2}$ Iscte - Instituto Universitário de Lisboa, Centro de Investigação e Estudos de Sociologia (CIES-Iscte). Lisboa, Portugal. ${ }^{3}$ Iscte - Instituto Universitário de Lisboa / Centro de Investigação e Estudos de Sociologia (CIES-Iscte); Universidade Aberta (UAb), Lisboa, Portugal.
} 
Abstract: The impact of the COVID-19 pandemic has led to the closure of schools around the world. Ministries, state governments, public and private bodies were suddenly forced to convert the entire educational process in order to seek that millions of students continue their training processes from their homes. From face-to-face, it transited to online, in the form of remote emergency teaching, and challenged teachers to rethink methodologies and pedagogical practices, in an attempt to develop learning situations in digital environments. This article, based on an exploratory analysis, seeks to understand how this transition from face-to-face to digital regime was carried out in Portuguese and Brazilian basic education, namely with regard to the preparation of both teachers and their schools. The answers obtained through the application of a questionnaire survey to 300 teachers allowed a perception of similarities and differences in the approach to promoting quality education in times of a pandemic.

Keywords: Secondary education. Emergency remote education. COVID-19. Teacher digital competence.

Resumen: El impacto de la pandemia de COVID-19 ha provocado el cierre de escuelas en todo el mundo. Ministerios, gobiernos estatales, organismos públicos y privados se vieron obligados repentinamente a reconvertir todo el proceso educativo para que millones de estudiantes pudieran continuar sus procesos de formación desde sus habitaciones. Del presencial, se transitó al online, en forma de enseñanza remota de emergencia, desafiando a los docentes a repensar metodologías y prácticas pedagógicas, buscando desarrollar situaciones de aprendizaje en entornos digitales. Este artículo, a partir de un análisis exploratorio, busca comprender cómo se llevó a cabo esta transición del régimen presencial al digital en la educación básica portuguesa y brasileña, es decir, en lo que respecta a la preparación tanto de los profesores como de sus escuelas. Las respuestas obtenidas mediante la aplicación de un cuestionario a 300 docentes permitieron percibir similitudes y diferencias en el enfoque para promover una educación de calidad en tiempos de pandemia.

Palabras clave: Educación secundaria. Educación remota de emergencia. COVID-19. Competencia digital docente.

\section{INTRODUÇÃO}

Vivem-se, atualmente, tempos onde a relação entre Tecnologias Digitais e Educação ganhou um novo significado. Apesar de o debate sobre a interação entre tecnologias e educação e sobre a mais valia dos recursos digitais para potenciar o processo educativo ser já extenso, a pandemia que se estendeu a todo o mundo a partir do início de 2020 mostrou que a preparação dos professores e dos estudantes para fazer um uso pedagógico do digital em prol da continuidade da educação era fundamental.

De facto, o Fórum Económico Mundial apontava já em 2015 para a importância da Tecnologia Digital, a importância de saber usá-la no desenvolvimento de competências transversais e como isso é fundamental no mundo atual (WEF, 2015). Dois anos antes, em 2013, era publicado o Manifesto Onlife, a partir de um projeto organizado pela Comissão Europeia, defendendo o fim 
da distinção entre offline e online, usando o neologismo onlife para se referir a uma nova realidade hiperconectada onde não tem sentido essa distinção (FLORIDI, 2015).

Porém, transportar essa realidade hiperconectada para um cenário escolar que, de um momento para o outro, deixou de decorrer entre os muros físicos das salas de aula, ou de fluir indistintamente entre ambientes presenciais e não presenciais, assumiu-se uma tarefa complexa. Por um lado, a necessidade de não deixar que a Escola parasse e, por outro, a importante tarefa de "não deixar nenhum aluno para trás" tornaram-se objetivos a cumprir num curtíssimo espaço de tempo. Em março de 2020, fruto da pandemia COVID-19, Portugal e o Brasil viram fechar a escola física e abrirem-se as janelas digitais nas casas de professores e de alunos.

Este trabalho visa compreender como foi realizada essa transição do regime presencial para o regime digital na educação básica portuguesa e brasileira, nomeadamente no que diz respeito à preparação dos professores e das suas escolas para a realização desta mesma transição e o que fizeram as escolas para acompanhar os seus estudantes e garantir que a nenhum deles ficaria vedado o acesso à educação.

Nesta comparação entre Portugal e o Brasil, considera-se interessante e pertinente aferir se esta transição se operou nos mesmos moldes e se as dificuldades e as soluções encontradas apresentam diferenças entre os dois países.

\section{CONTEXTO: EDUCAÇÃO BRASILEIRA E PORTUGUESA DURANTE O PERÍODO DE PANDEMIA COVID-19}

Pouco mais de 100 anos depois da pandemia conhecida como "Gripe Espanhola", que matou milhões de pessoas e paralisou economia e sociedade, forçando o encerramento de escolas como medida preventiva da disseminação da doença, nova pandemia toma conta do mundo. Se, no início do ano de 2020, um pouco por toda a parte se observavam os primeiros acontecimentos na China, sem perspectiva de que essa situação se alastrasse a todos os continentes, bastaram poucas semanas para que tudo se alterasse.

Durante o mês de março de 2020, dia após dia, escolas de todo o mundo encerravam as suas portas físicas. Portugal e Brasil encontram-se entre os países que o fizeram (Figura 1), primeiro de uma forma opcional, mas, pouco depois, os Governos dos dois territórios assumiram que manter as escolas abertas contribuiria para uma ainda maior disseminação da doença. 
Figura 1- Estudantes no mundo afetados pelo encerramento das escolas à data de encerramento em Portugal (16/03/2020) e no Brasil (25/03/2020)

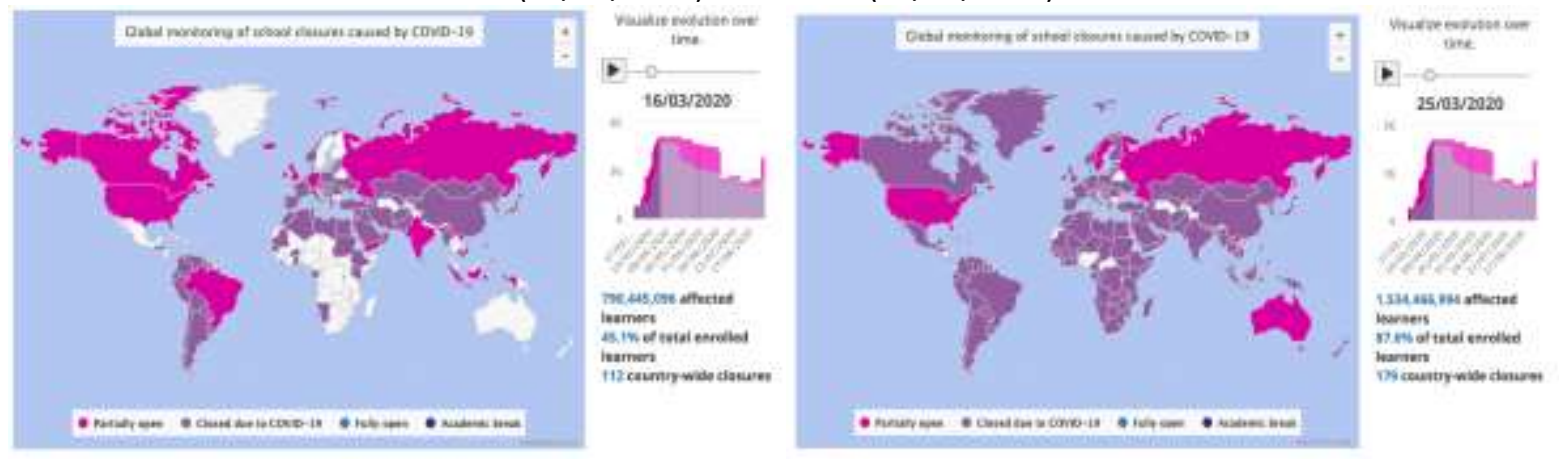

Fonte: https://en.unesco.org/covid19/educationresponse

Como referem Sanz, Gonzállez e Capilla (2020), as circunstâncias excecionais que esta pandemia provocou colocaram à prova os sistemas educativos no mundo inteiro que, de um momento para o outro, tiveram a necessidade de converter todo o processo educativo de forma a procurar que milhões de estudantes continuassem os seus processos formativos, mesmo confinados aos seus domicílios.

Resultado das diferenças de organização política em Portugal e no Brasil, também as políticas públicas de resposta a esta pandemia na Educação Básica seguiram caminhos com algumas diferenças. Em Portugal, a centralização da educação básica colocou nas mãos do Ministério da Educação, em primeiro lugar, a decisão de encerramento de todas as escolas do país (no dia 16 de março de 2020) e, na sequência dessa decisão, a preparação de um conjunto de orientações e de formação em ambientes digitais para que os docentes conseguissem transitar para um formato completamente digital, não deixando de acompanhar todos os estudantes que não tivessem acesso a dispositivos digitais ou internet nos seus domicílios.

Deste modo, é criado pelo Ministério um site de apoio às escolas (disponível na mesma data do encerramento da escola), são preparados e enviados a toda a comunidade escolar guias de apoio ao funcionamento das escolas durante o período de encerramento físico e é pedido aos diretores de escola que identifiquem todas as necessidades de apoio aos estudantes (quer a nível tecnológico quer, também, a nível social). É enviado um roteiro às escolas com princípios orientadores para o ensino a distância, dando liberdade a cada escola para desenvolver o seu plano com várias etapas: definição das estratégias de gestão e liderança, estratégia e circuito de comunicação, modelo de ensino a distância, plano de monitorização e avaliação, constituição de equipas de apoio para dar respostas e organizar meios e ferramentas. Finalmente, é feita uma parceria com a Universidade Aberta para preparação e execução de formação docente na área do uso das tecnologias digitais. 
Sendo a Universidade Aberta a única instituição superior pública de educação a distância foi desenhado o curso para a Docência Digital em Rede com o objetivo de promover, nos professores do ensino não superior, competências na área da educação a distância (MOREIRA; HENRIQUES; BARROS, 2020). Neste sentido, o curso em referência providenciou um espaço de reflexão sobre as alterações pedagógicas necessárias para a transição e adaptação à educação a distância, bem como sobre as potencialidades que a tecnologia oferece e que permitem ir além na resposta pedagógica emergencial.

No Brasil, devido à descentralização das políticas educativas e à necessária articulação entre os poderes Federal e Estadual, as orientações são emanadas pelo Governo central, mas, em alguns casos, sujeitas a definição ou aprovação ao nível estadual. Em 17 de março de 2020 a Portaria n.o 343 do Ministério da Educação Brasileiro “dispõe sobre a substituição das aulas presenciais por aulas em meios digitais enquanto durar a situação de pandemia do Novo Coronavírus - COVID-19", ao que se vão seguir a publicação de pareceres por parte dos Governos Estaduais, sobre quem recaiu a responsabilidade pela apresentação de iniciativas direcionadas para a substituição das aulas presenciais por aulas remotas ou de adoção da modalidade de educação a distância (ARRUDA, 2020). Nesse sentido, os Conselhos Estaduais de Educação e vários Conselhos Municipais de Educação "emitiram resoluções e/ou pareceres orientativos para as instituições de ensino pertencentes aos seus respectivos sistemas sobre a reorganização do calendário escolar e uso de atividades não presenciais" (Parecer 5/2020 do Conselho Nacional de Educação, homologado parcialmente em 29 de maio de 2020).

Quer no Brasil quer em Portugal, e na maioria dos casos, estudantes que tinham acesso a recursos tecnológicos e ligação à Internet, tiveram acesso a aulas e a material didático em tempo real. Estudantes sem recursos nem ligação, receberam material impresso pelas escolas. Esta situação, no imediato, aumentou os fossos entre a comunidade escolar, os que possuíam meios tecnológicos para acompanhar a lecionação dos conteúdos e os que não tinham e tiveram que acompanhar de formas muito mais limitadoras.

Esta transição para um ensino digital, apesar da consciência desde logo de que não seria acessível pela totalidade dos estudantes, converteu-se numa realidade de um dia para o outro. Porém, na maior parte dos casos, veio a constituir-se numa transposição de práticas da educação presencial para um ensino remoto, longe, por isso, de uma modalidade de educação a distância e tendo como principal objetivo minimizar os prejuízos decorridos da suspensão das aulas presenciais. Na maioria dos casos, os mesmos exercícios realizados de forma presencial foram replicados para o 
online, mimetizando modelos e práticas pedagógicas para ambientes educativos onde a presença $\mathrm{e}$ a forma de comunicar são diferentes, o feedback e o apoio são também realizados de outra forma, os tempos de concentração e empenho nas atividades também, assim como a autonomia dos alunos.

De facto, o que se começou a praticar na escola foi um ensino remoto, porque de facto há um completo afastamento físico entre os principais atores do processo educativo (professores e estudantes) e emergencial pois colocou-se em prática da noite para o dia, sem uma efetiva reflexão pedagógica. Como refere Tomazinho (2020), “O que está acontecendo é um planejamento pedagógico in real time (em tempo real). Nunca as escolas tiveram que experimentar tanto, e gestores e professores tomarem decisões tão rápidas." (online)

O ensino remoto emergencial resulta, pois, de uma resposta imediata a uma crise, concretamente a provocada pela pandemia COVID-19, com o objetivo de manter as atividades letivas. Traduz-se numa mudança rápida dos processos de ensino e aprendizagem presenciais para modelos alternativos, tecnologicamente mediados. O conceito é proposto por Hodges, Moore, Lockee, Trust e Bond (2020) no sentido de marcar as diferenças entre outros conceitos ainda em estabilização. Tal é o caso da educação a distância que resulta de um desenho pedagógico cuidadosamente planificado, assente num modelo sistemático que orienta o seu desenvolvimento (MEANS; BAKIA; MURPHY; 2014). Daqui resulta um ecossistema educacional online robusto e bem planeado com o uso inovador de ferramentas digitais nos processos de ensino e aprendizagem. Ao mesmo tempo que os processos e decisões associadas ao desenho pedagógico impactam na qualidade das ofertas educativas, também o recurso aos media digitais têm vindo a alterar os modos como os estudantes se relacionam entre si e com os conteúdos.

A verdade é que a transição dos ambientes presenciais para os virtuais foi a solução encontrada para que a educação não parasse, deixando milhões de estudantes sem possibilidade de construir os seus conhecimentos (o que, por exemplo, resultou do encerramento das escolas durante a pandemia da "Gripe Espanhola", que durante meses deixou a quase totalidade das crianças sem qualquer solução para fazer face a esse mesmo encerramento). O modelo adotado tem as suas limitações, sim, uma vez que em muitos casos não assumiu a necessidade de um planejamento preconizado pelo design instrucional/educacional, porém teve a mais valia de permitir a continuidade dos estudos e levar professores e estudantes a aprender a utilizar novas ferramentas como suporte ao processo de ensino e de aprendizagem (SANTO; DIAS-TRINDADE, 2020). 
Reimers e Schleicher (2020) realizaram um importante estudo a partir do levantamento de necessidades de praticamente 100 países, que lhes permitiu elaborar uma lista com 25 áreas educativas a ter em conta na resposta à COVID-19, em conjunto com 13 pontos que os autores consideram como prioridade para os governantes de cada país. A partir dos resultados obtidos, importa salientar algumas ideias: a grande prioridade deve ser assegurar a continuidade da educação, ainda que isso seja um desafio sobretudo devido aos constrangimentos tecnológicos (veja-se que, por exemplo, enquanto em Portugal é indicada uma taxa superior a 90\% no que diz respeito ao acesso dos estudantes a um computador, e de quase $100 \%$ no que diz respeito ao acesso à internet, no Brasil a taxa ronda os $60 \%$ para o acesso a computador e os $90 \%$ no que toca a acesso à internet). Porém, este desafio tecnológico é visto pelos respondentes também como uma oportunidade. De facto, como Figueiredo (2020) refere, este caminho nunca havia sido explorado. Porém, o autor salienta que "o que isto significa é que atravessamos um raro momento de valorização. Uma oportunidade única para os professores examinarem as suas próprias práticas à luz dos desafios que a distância lhes coloca e tornarem-se ainda melhores professores." (online)

De facto, o fosso digital que já há algum tempo vem sendo internacionalmente referido como promotor de desigualdades começa desde logo na maior ou menor capacidade de acesso aos recursos tecnológicos e digitais. Para além disso, naturalmente que os que estão mais habituados a fazer um uso quotidiano do digital estavam em vantagem em março de 2020, quer fossem docentes, quer estudantes (SANGRÀ, 2020). Porém, este é o momento para compreender a importância de um uso pedagógico do digital. Este "fosso institucional", quer da capacidade da escola para assegurar os recursos, quer da parte dos docentes para usar métodos didáticos assentes em recursos ou plataformas digitais, quer mesmo a capacidade de os estudantes compreenderem como usar a tecnologia digital para desenvolver as suas aprendizagens, pode determinar, no momento que vivemos, o acentuar das desigualdades em educação.

No caso dos docentes, os estudos de PISA de 2018 apresentados no trabalho de Reimers e Schleicher (2020) mostram que ainda há um longo caminho a percorrer no que diz respeito à competência digital docente. No caso português os resultados indicam que os estudantes entendem, em média, que apenas pouco mais de $60 \%$ dos professores têm as competências técnicas e pedagógicas necessárias para integrar a componente digital nos processos educativos e, no Brasil, essa percentagem desce para cerca de $50 \%$.

Este estudo acompanha os resultados de outros trabalhos na área das competências digitais (DIAS-TRINDADE; MOREIRA; NUNES, 2019), realizados quer em Portugal (DIAS-TRINDADE; 
MOREIRA, 2020), quer no Brasil (CORRÊA; NUNES; DIAS-TRINDADE, 2020), que demonstram que as competências digitais dos professores se encontram em níveis medianos (B1/Integrador - nível 3 de uma escala com 6 níveis), demonstrando que, apesar de já usarem tecnologias digitais em diferentes contextos e as integrarem nas suas práticas educativas, ainda precisam compreender como rentabilizar o seu uso para potenciar, de facto, o processo educativo.

A compreensão das diferentes áreas que compõem as competências digitais docentes assume-se hoje de particular importância. De facto, a competência digital constrói-se a partir de um caminho evolutivo entre o letramento digital e a fluência digital, variável consoante as áreas de uso do digital (trabalho autónomo, ensino e aprendizagem, avaliação, comunicação ou capacitação dos estudantes) e configura-se na capacidade de dominar conhecimentos básicos e por vezes limitadores da capacidade de trabalho em ambientes educativos digitais ou, de forma mais avançada e próxima da fluência, quando os docentes "se sentem capazes e confiantes na distinção entre quais as melhores ferramentas ou estratégias digitais usar, em diferentes momentos e, sobretudo, como delas fazer uso para melhor atingir os seus objetivos" (DIAS-TRINDADE; FERREIRA, 2020, p. 183).

Naturalmente, não pode esquecer-se a importante questão do acesso dos estudantes aos conteúdos digitais disponibilizados pelos professores durante este período, questão que tem sido alvo de preocupação e referência pelos variados estudos que têm sido publicados nos últimos meses, bem como referidos nas publicações que instituições internacionais como a UNESCO têm disponibilizado (destaca-se o apoio deste organismo, nomeadamente na criação da Global Education Coalition - https://en.unesco.org/covid19/educationresponse/globalcoalition - promover oportunidades de aprendizagem para todas as crianças e jovens durante este período da pandemia COVID-19).

O estudo que de seguida se apresenta foca-se nesta articulação entre o cenário disponível na Educação Básica portuguesa e brasileira e as estratégias adotadas para suprimir dificuldades quer ao nível do acesso por parte dos estudantes, que no quer diz respeito à competência digital docente. Dois países que falam a mesma língua mas com dimensões demográficas, territoriais, sócioeconómicas e políticas diferentes viram-se, na mesma altura, frente a uma situação inesperada e que veio alterar a forma como se pensa a educação e o papel que a tecnologia digital pode desempenhar para que, como refere a UNESCO, "a educação nunca pare". Analisar as percepções de docentes portugueses e brasileiros, da Educação Básica, em conjunto, permite um olhar sobre 
semelhanças e diferenças na abordagem à promoção de uma educação de qualidade em tempos de COVID-19.

\section{METODOLOGIA DO ESTUDO}

\subsection{RECOLHA DE DADOS E PARTICIPANTES}

Os dados apresentados e analisados no presente artigo resultam da aplicação de um inquérito por questionário construído nos meses de março e abril de 2020, início do período crítico da pandemia mundial resultante da propagação da COVID-19. Divulgado e aplicado online, através das redes sociais em grupos de docentes brasileiros e portugueses, o questionário é composto por questões que refletem as dimensões que se pretendiam analisar:

a) Tipo de plataformas digitais utilizadas,

b) Estratégias de escola e formação docente,

c) Brecha digital,

d) Análise de casos específicos.

Foram rececionadas 300 respostas de docentes de Ensino Superior e da Educação Básica durante os meses de maio, junho, julho e agosto de 2020. Neste artigo, os dados a trabalhar referem-se apenas ao Ensino Básico (sendo nesta amostra incluídas as respostas de docentes que trabalham quer no Básico, quer no Ensino Superior). Assim, e num universo de 231 respostas válidas, 92 pertencem a docentes do Brasil (39,8\%) face a 139 respostas pertencentes a docentes portugueses $(60,2 \%)$.

\subsection{1. Ética na pesquisa}

O projeto de investigação na base do presente artigo, não tendo sido submetido à apreciação de uma comissão de ética, não deixou de seguir as orientações éticas constrantes da Carta Ética publicada pela Sociedade Portuguesa de Ciências da Educação (SPCE, 2014). Durante todo o processo investigativo as autoras mantiveram elevados níveis de vigilância e autoreflexividade em relação às questões éticas, tal como defendido por (MAINARDES; CARVALHO, 2019).

$\mathrm{Na}$ linha da autodeclaração de princípios e de procedimentos éticos na pesquisa, importa clarificar os seguintes aspetos: 
a) O caráter voluntário da participação e a possibilidade de desistência. As respostas foram voluntárias, podendo o preenchimento do questionário ser interrompido a qualquer momento (BASSEY; OWAN, 2019).

b) A confidencialidade e privacidade. As respostas são anónimas e os dados são trabalhados em bloco. Os resultados destinam-se apenas a responder aos objetivos da investigação em curso (BASSEY; OWAN, 2019; CRESWELL, 2007).

c) Divulgação da informação. A publicação dos resultados é a melhor forma de divulgação numa investigação onde efetivamente não existe registo ou contato com os respondentes (lembramos que a recolha de dados foi feita online, através das redes sociais) (BEARDSLEY; SANTOS; HERNÁNDEZ-LEO; MICHOS, 2019).

d) Benefícios e respeito pela integridade. Os dados recolhidos e os resultados obtidos não representam qualquer tipo de constrangimento para os participantes (LINDER; FARAHBAKHSH, 2020). Ao contrário, acreditamos que o aumento do conhecimento da perspectiva dos professores portugueses e brasileiros sobre o ensino remoto de emergência traduz-se em benefícios para os contextos e as práticas dos professores em geral (não apenas dos participantes). Traduz-se ainda em contributos para o campo da investigação educacional.

e) Declaração de interesses. As autoras declaram não ter conflitos de interesses.

\subsection{ANÁLISE DE RESULTADOS}

\subsubsection{TIPO DE PLATAFORMAS DIGITAIS UTILIZADAS}

No Brasil, e nas percentagens com maior expressão, as plataformas digitais mais utilizadas foram a Microsoft Teams (67,4\%), a Google Classroom (26,1\%), a Moodle e o Zoom (ambos com 13\%). Em Portugal, por sua vez, a Google Classroom surge como a plataforma mais escolhida (50,4\%), seguida pela Microsoft Teams e pelo Zoom (ambos com 40,3\%), a Moodle foi selecionada por 15,1\% da amostra e a Classdojo por 7,2\%. (Gráfico 1) 
Gráfico 1 - Plataformas digitais usadas

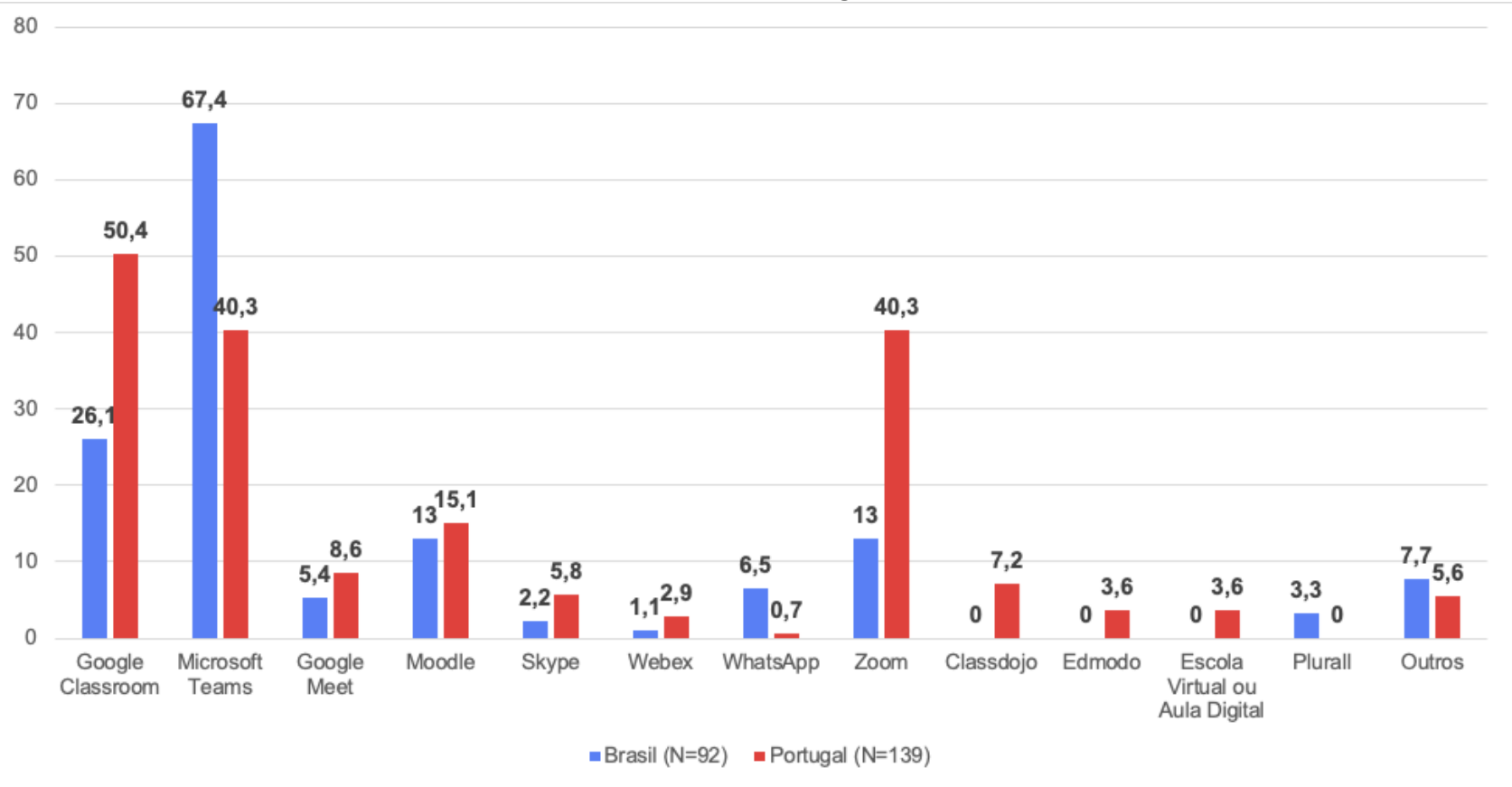

Fonte: Elaborado pelas autoras.

Verifica-se, deste modo, uma clara preferência pelas plataformas educativas integradas mais conhecidas, da Microsoft e da Google, assumidamente utilizadas pela maioria dos respondentes, provavelmente por constituírem espaços onde era possível agregar diferentes atividades e estabelecer um circuito organizado de comunicação entre professores e estudantes. Em Portugal o Zoom foi mais utilizado do que no Brasil, podendo associar-se a uma preferência pelo uso da plataforma Google Classroom.

\subsubsection{ESTRATÉGIAS DE ESCOLA E FORMAÇÃO DOCENTE}

Quer no Brasil, quer em Portugal, a escolha da plataforma digital a utilizar pertenceu maioritariamente às Escolas, sendo que apenas 14,1\% dos docentes brasileiros tiveram liberdade de escolha face a $26,6 \%$ de docentes portugueses que também puderam optar. Grande parte dos docentes, em ambos os países (62\% no Brasil e $82 \%$ em Portugal), contou com uma equipa técnicopedagógica criada pelas próprias instituições para prestar apoio durante o período de ensino remoto de emergência.

Estas respostas refletem as iniciativas tomadas nos dois países. Em Portugal, o primeiro documento orientador data de 27 de março de 2020, intitulado "ROTEIRO - 8 Princípios Orientadores para a Implementação do Ensino a Distância (E@D) nas Escolas", apresentando, no 
ponto 6.3, a indicação para, em cada Agrupamento de Escolas ou Escola Não Agrupada, de "disponibilizar apoio técnico e pedagógico aos professores, tendo em vista a utilização dos meios tecnológicos". No Brasil coube a cada Estado definir a forma como as escolas se organizaram, resultando, naturalmente, em diferenças consoante a zona.

A formação ou experiência em ambientes digitais dividiu as respostas no Brasil, com 51,1\% dos docentes a confessarem que já tinham experiência prévia. Em Portugal, essa percentagem é superior, com 66,9\% dos professores a conhecerem já o trabalho docente em ambientes digitais. Estes números parecem estar diretamente relacionados com a procura de formação durante o período da pandemia em análise: $69,6 \%$ dos docentes brasileiros procuraram realizar formação para se sentirem mais confortáveis durante o período de educação totalmente digital, enquanto 79,9\% dos professores portugueses procuraram também capacitar-se no que a formação para a docência online diz respeito.

Curioso é que, quando analisados os resultados dos estudos de PISA 2018 (apesar de se referirem a dados com cerca de dois anos), referidos no texto de Reimers e Schleicher (2020), quer os estudantes brasileiros, quer os portugueses situam nos $50 \%$ (no caso do Brasil ligeiramente acima e no de Portugal ligeiramente abaixo) a existência de recursos para os professores saberem usar o digital nas suas práticas pedagógicas, a existência de incentivos para que os docentes façam formação nesta área e que haja efetivo apoio técnico para os docentes que precisam de utilizar recursos e plataformas digitais na sua profissão.

Numa vertente mais institucional, $80,4 \%$ dos docentes no Brasil revelaram que as suas escolas apostaram no cumprimento das planificações anuais, sendo que apenas $16,3 \%$ focaram uma decisão de mero reforço das aprendizagens. A opção por outro tipo de decisão é residual no Brasil, ganhando outra dimensão em Portugal: 55,4\% dos professores em Portugal responderam que nas suas escolas se optou pelo cumprimento das planificações anuais, $28,8 \%$ assinalaram o reforço das aprendizagens e 15,8\% avançaram com outras opções (em que se incluiu alterar a planificação anual, falta de indicações claras ou as escolas deixarem a decisão ao critério de cada grupo disciplinar).

Estas respostas denotam uma maior influência da administração escolar das escolas brasileiras no desenvolvimento das atividades pedagógicas por parte dos professores do que terá acontecido em Portugal, onde o Ministério da Educação (2020) indicava ser importante que, "independentemente de uma seleção de plataforma específica de apoio ao ensino e à aprendizagem por cada Escola, deverão ser rentabilizados os meios tecnológicos com os quais todos estão 
familiarizados" (p. 6) e que cabe a cada escola "em função da fase em que se encontre e da sua realidade, refletir sobre os princípios apresentados e desenvolver o seu Plano E@D, encontrando as respostas mais adequadas e potenciadoras do sucesso educativo dos alunos." (p. 1).

\subsubsection{BRECHA DIGITAL}

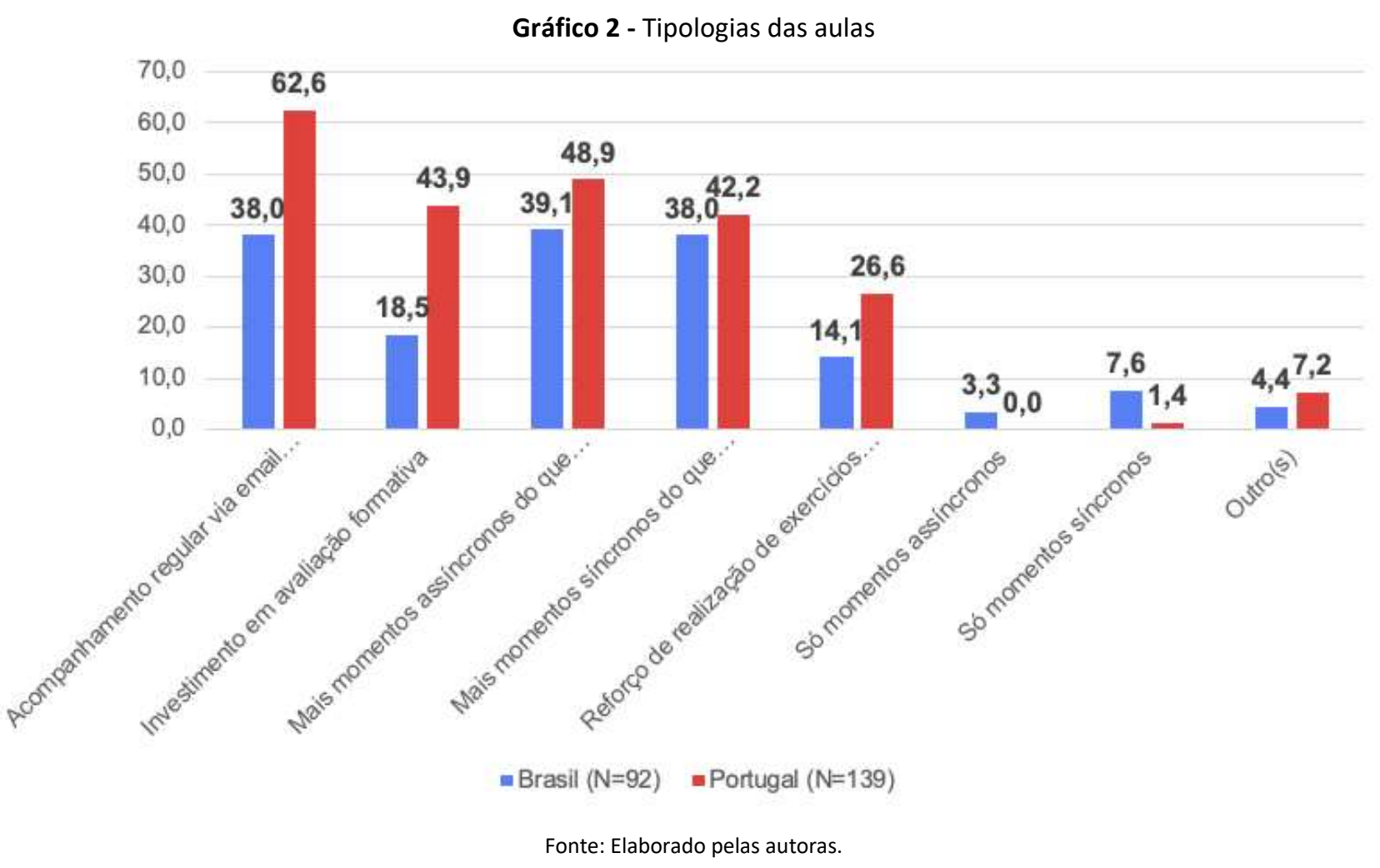

As tipologias de aulas são, em geral, idênticas no Brasil e em Portugal, onde prevaleceram os momentos síncronos, assíncronos e o acompanhamento regular por e-mail. A única exceção aparece nos momentos exclusivamente assíncronos, que só foram opção para professores no Brasil. Ainda assim, com uma expressão residual (3\%).

Neste quadro de mudança e adaptação emergem as lideranças dos professores nos processos de ensino e aprendizagem, diversificando modos de atuação (cada respondente assinalou mais do que uma opção) no sentido de sustentar o clima da relação pedagógica (MASSANO; HENRIQUES, 2018). A brecha tecnológica deve, então, ser repensada já que no período de encerramento das escolas se verificou uma tendência de aproximação das práticas de uso do digital entre professores e alunos. Nos alunos aumentou o uso para fins pedagógicos (como demonstram os resultados deste estudo), nos professores (como na população em geral) aumentou o uso para fins de sociabilidade e recreativos. Esta mudança de práticas terá certamente impactos nos níveis 
de fluência digital das populações e evidencia que esta tende a tornar-se um recurso transversal, fundamental e crítico para os indivíduos nas múltiplas esferas das suas vidas. Aí se encontra inscrita a conviç̧ão de que a experiência e a extensão do uso dos media digitais têm poder explicativo, pelo menos, equivalente ao da idade (HELSPER; ENYON, 2010; BARROS; HENRIQUES, 2011).

\subsubsection{ANÁLISE DE CASOS ESPECÍFICOS}

A opinião dos participantes sobre se se sentem mais aptos para trabalhar em ambientes educativos digitais, depois do trabalho desenvolvido durante este período, vem demonstrar que a experiência foi fundamental, quer como forma de colocar em prática estratégias diversificadas de uma forma mais continuada, quer porque foi necessário perder o receio, quer também porque verificaram que é, de facto, possível ensinar e aprender com qualidade neste tipo de ambientes. Efetivamente, conforme se pode verificar no Gráfico 3, 67,4\% dos participantes brasileiros e 75,5\% dos participantes portugueses partilham dessa opinião, à qual segue a opinião de que a realização de formação durante este período teve também efeitos positivos (correspondendo a 10,9\% das respostas brasileiras e $7,9 \%$ das portuguesas).

Gráfico 3 - Opinião sobre aptidão para uso de ambientes educativos digitais depois do trabalho desenvolvido durante

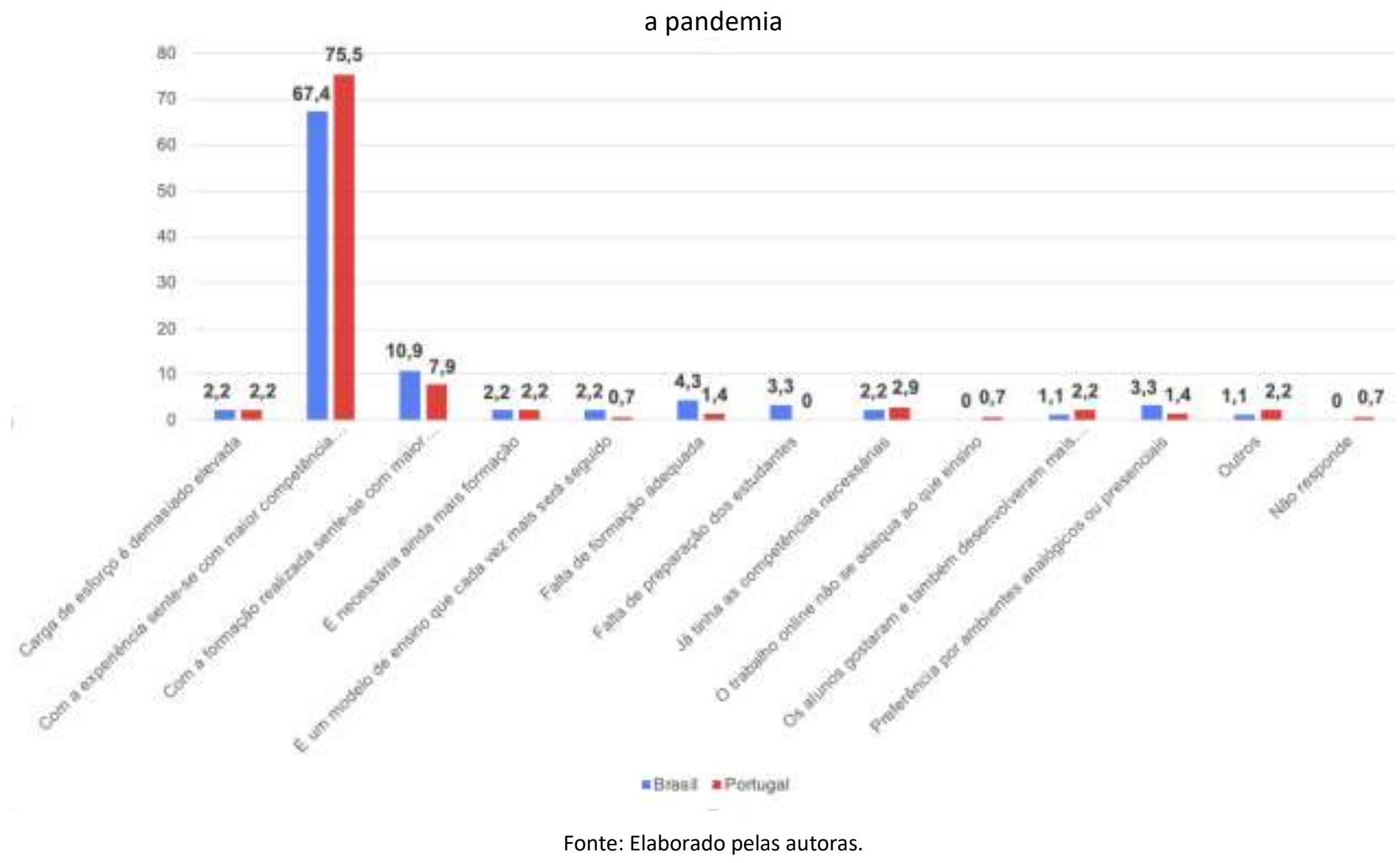


Naturalmente, alguns docentes continuam a considerar que é necessária mais formação (2,2\% tanto da parte de brasileiros, como de portugueses) ou que a que realizaram não foi ao encontro das suas reais necessidades (4,3\% dos participantes do Brasil e 1,4\% dos de Portugal). No entanto, as opiniões e justificações apresentadas parecem apontar para questões inerentes a qualquer processo imediatista ligado a uma "migração" forçada de espaços, práticas, recursos e metodologias. Situação essa que polariza perspectivas: de um lado obtemos respostas demonstrativas de uma visão híbrida, interdisciplinar, disruptiva e de aprendizagem e, na vertente oposta, surgem as respostas apoiadas em visões presas a um movimento lento (ou mesmo nulo) de implementação de cenários pedagógicos com utilização do digital (quer devido a políticas educativas, escassos recursos digitais, fraca capacitação docente ou falta de visão de direções de escolas, agrupamentos ou estabelecimentos). A título de exemplo desta polarização de posições, veja-se algumas respostas mais desenvolvidas no que toca a sentirem-se mais aptos a trabalhar em ambientes educativos digitais após a experiência do ensino remoto emergencial:

“Foi possível compreender que há inúmeras ferramentas para melhorar o conteúdo presencial e que em muitos casos o que falta é motivação para implantar esses recursos";

"Esta nova realidade levou-nos a adaptar o ensino com recurso a novas tecnologias. Levou a ligar-nos em rede. A ser uma professora mais orientadora das aprendizagens dos alunos. A interdisciplinaridade é essencial";

"As tecnologias fazem parte cada vez mais da vida dos nossos jovens. Atualmente já diversas empresas trabalham recorrendo a este método. Seguramente os nossos alunos terão de estar preparados para essa realidade. Apesar de fazer muita falta o contato presencial";

"Porque a aprendizagem é uma troca de saberes. E senti um distanciamento dos alunos na forma remota";

"O distanciamento não permite a consolidação dos conteúdos nem a percepção real da aquisição das aprendizagens por parte dos alunos. A presença é fundamental".

A Figura 2 é uma nuvem de palavras realizada a partir das respostas dadas pelos participantes a esta questão, ilustrando, uma vez mais, a importância dada à experiência, às aprendizagens realizadas através da formação e das práticas, tudo contribuindo, sobretudo, para maior conhecimento nesta área e para uma sensação de que no futuro haverá mais espaço para aprender ainda mais e para fomentar um uso pedagógico dos recursos e das ferramentas digitais. 
Figura 2 - Nuvem de palavras sobre aptidão para uso de ambientes educativos digitais depois do trabalho desenvolvido durante a pandemia

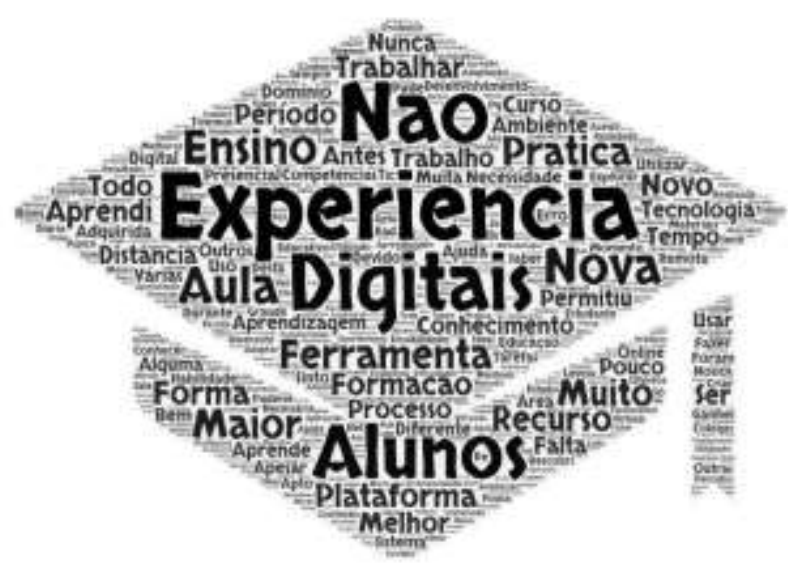

Fonte: Elaborada pelas autoras.

As respostas ao questionário demonstram também, sem margem para dúvidas, que as escolas brasileiras e portuguesas não estavam preparadas para a súbita transição para a distância, sendo por isso normal a dificuldade de adaptação por parte dos professores (e também dos alunos). Em comum, e como uma das maiores dificuldades sentidas, perfila-se o "distanciamento dos alunos a nível pedagógico" (18,5\% no Brasil e 10,8\% para Portugal). Problemas técnicos, inexperiência no trabalho em ambientes digitais ou dificuldade na preparação de materiais são outras das dificuldades referidas (Gráfico 4). 
Gráfico 4 - Opinião sobre a maior dificuldade sentida durante o período de pandemia

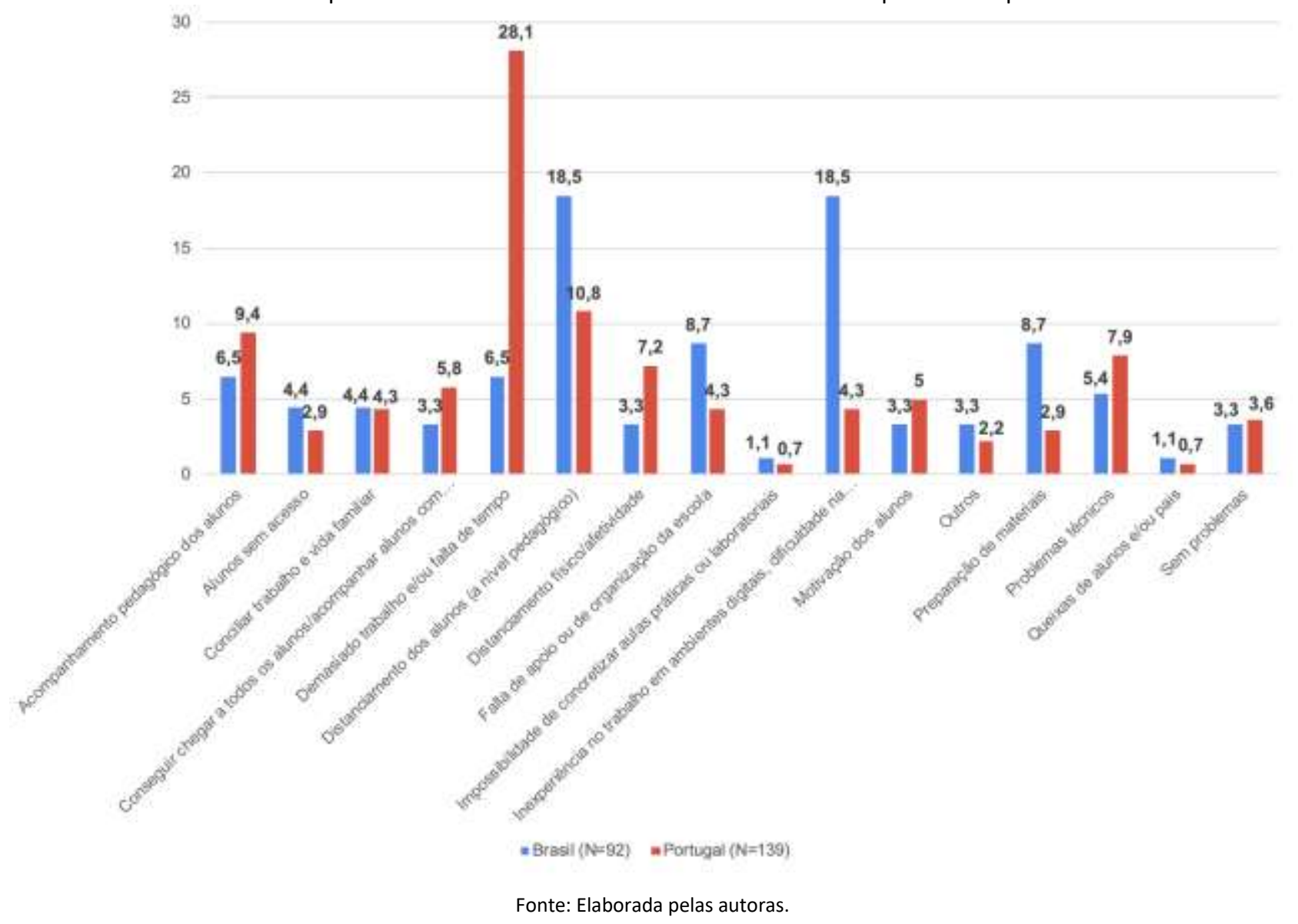

Os aspetos negativos ou dificuldades apontam, assim, para questões relacionadas com as assimetrias e diferentes condições socioeconómicas e familiares dos alunos, falta de assistência, apoio ou supervisão por um adulto ou encarregado de educação, falta de equipamentos e ligação à Internet, desconhecimento de ferramentas e softwares quer por alunos, quer por professores e pais, ou falta de informação sobre softwares em geral e recursos educativos digitais de acesso aberto e de utilização gratuita.

Tal situação é ainda mais perceptível em respostas extensas sobre qual a maior dificuldade sentida, de que são exemplo as seguintes afirmações:

"Tive dificuldade em adaptar conteúdos ao sistema remoto e acompanhar a produção dos alunos";

"Dificuldade em compreender as diferentes metodologias para melhor aplicar no ambiente virtual, uma vez que, no primeiro momento adaptamos as práticas de aulas presenciais no ambiente virtual";

"O incumprimento por parte dos alunos e encarregados de educação. $O$ excesso de horas no computador/telefone. E a despesa da net/tarifário do telemóvel";

"O contacto com diversos alunos que não tinham internet, computador ou câmara. Muitos não sabiam trabalhar com recursos digitais. E muitos pais também não $\mathrm{e}$ não podiam nem sabiam dar apoio". 
A partir das dificuldades apontadas elaborou-se uma nuvem de palavras (Figura 3) onde se destacam os aspetos referidos.

Figura 3 - Nuvem de palavras sobre as principais dificuldades sentidas durante o período da pandemia

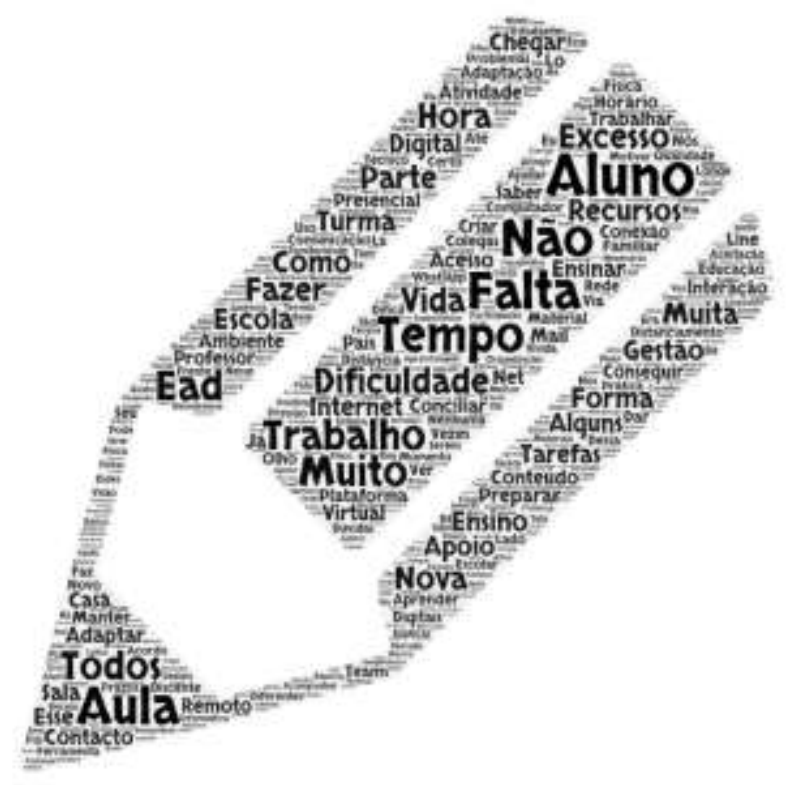

Fonte: Elaborada pelas autoras.

As desigualdades sociais, educacionais e de saúde emergem deste período fortemente associadas às questões do acesso ao digital. No entanto, vão muito para além deste e devem ser (re)pensadas tendo em vista uma sociedade mais inclusiva e justa (WILLIAMSON; EYNON; POTTER, 2020).

\section{CONSIDERAÇÕES FINAIS}

Trabalhar a partir de casa durante uma crise pandémica tem implicações profundas na relação com o tempo e o espaço. O trabalho (digital) dos professores nestas circunstâncias não escapa aos condicionalismos de um mapeamento complexo entre o offline e o online, entre o possível e o desejável. A ideia corrente de que o digital torna mais fáceis os processos de ensino e aprendizagem foi posta à prova e, em certa medida, contrariada.

No presente estudo procuramos estabelecer uma comparação entre professores do Brasil e de Portugal no sentido de melhor compreendermos as dinâmicas de adaptação e/ou de transformação operadas durante este período emergencial. Percebemos então que, de um modo 
geral, foram utilizadas as mesmas tecnologias e plataformas, o que remete para uma perspetiva geopolítica com enfoque nas grandes empresas de tecnologia e nas vantagens comerciais que retiram da expansão da educação (KNOX, 2020). Neste sentido, as plataformas globais estão a ser fortalecidas simultaneamente com as organizações políticas que procuram no capital humano o principal resultado da educação.

Sobre o papel das escolas no apoio ao processo de transição, os resultados mostram que a administração escolar e central orientou a transição em ambos os países, com algumas oscilações não significativas. Ainda assim terá sido determinante a formação já desenvolvida pelos professores, assim como a capacidade revelada por estes de aprendizagem e de adaptação. Nas palavras de Stoll (2020) "Ter capacidade de aprender é estar verdadeiramente aberto para abraçar as transformações necessárias para enfrentar os desafios educacionais complexos que enfrentamos" (p. 422, tradução das autoras).

A equidade e inclusão de todos dos alunos têm sido uma preocupação educacional transversal. Mais recentemente, a inclusão tem sido apresentada sob um prisma abrangente, salientando o desenvolvimento da aprendizagem e participação de todos os alunos, em particular os mais vulneráveis à exclusão, mas não apenas os que apresentam deficiência ou dificuldades de aprendizagem. Pretende-se, assim, que as escolas promovam uma efetiva participação, pertença e equidade, em resposta às necessidades e potencialidades de todos os alunos e de cada um. No momento em estudo, a prioridade foi dada à relação pedagógica no sentido de apoiar os alunos em confinamento. Tal verificou-se tanto no Brasil como em Portugal. Esta perspectiva é consonante com a de Booth e Ainscow (2002) onde se aponta para a participação, valorização e aprendizagem de todos os estudantes, o que requer uma reestruturação das políticas educacionais e das práticas das escolas em resposta à diversidade, a remoção de barreiras que impeçam o acesso de todos à aprendizagem e participação e um foco nos valores e na comunidade e não apenas nos resultados.

As diferenças identificadas neste estudo, entre os dois países em análise, não são significativas. Podemos então referir que os resultados apontam para uma aprendizagem pela prática ('Learning by doing', DUFOUR et al., 2016) por parte dos professores. Além disso, terão sido levados a desenvolver e intensificar práticas colaborativas entre si no sentido de ultrapassar dificuldades e encontrar soluções. A construção de comunidades de prática dentro das escolas e de comunidades mais vastas permitindo às escolas colaborar com outras agências no sentido de melhorar as oportunidades educacionais e condições sociais nas suas localidades, remete também para a ideia de inclusão. Este é, pois, um aspeto crítico que merece maior atenção e reflexão no 
sentido de se conhecerem as mudanças em curso e as suas consequências a longo prazo na educação em geral e, em particular, nas práticas de ensino e aprendizagem com recursos digitais.

Os modelos de educação remota emergencial têm potencial de transformação dos sistemas educacionais, com efeitos muito para além da pandemia. Se, em muitos aspetos a mudança para a educação online foi aleatória e caótica, os resultados da investigação (onde incluímos o presente estudo) apontam para mudanças mais amplas com implicações a longo prazo. Designadamente na inovação das práticas pedagógicas, na procura de soluções tecnológicas mais ajustadas (e até customizadas) mas também na qualidade da educação a distância prestada.

Sabemos que a tecnologia não vai resolver as desigualdades sociais e, concretamente, educacionais. Mas sabemos também que poderá ter um papel facilitador se houver esquemas de acesso estrategicamente planeados de forma holística e a longo prazo. A experimentação ocorrida numa fase inicial da pandemia deve então, dar lugar a um outro nível no desenvolvimento das ofertas educativas de qualidade com todo o seu potencial de desenvolvimento do capital humano à escala global.

\section{REFERÊNCIAS}

ARRUDA, Eucidio Pimenta. Educação remota emergencial: elementos para políticas públicas na educação brasileira em tempos de Covid-19. Revista EmRede, v. 7, n. 1, p. 257-275, 2020.

BARROS, Daniela, \& HENRIQUES, Susana. Literacia virtual e ambientes e-learning. In DIAS, Paulo; OSÓRIO, José (Orgs.) Challenges 2011: Atas da Conferência Internacional de Tecnologias de Informação e Comunicação. 1. ed. Braga: Centro de Competência da Universidade do Minho, 2011. p. 1217-1226.

BASSEY, Asuquo Bassey, \& OWAN, Valentine Joseph. Ethical issues in educational research, management and practice. In OLOLUBE, P. N., \& NWIVI, G. U. (Eds.). Encyclopedia of instructional leadership, policy, and management. 1. ed. Port Hartcourt: Pearl Publishers International, 2019. p. 1287-1301.

BEARDSLEY, Marc, SANTOS, Patrícia, HERNÁNDEZ-LEO, Davínia, \& MICHOS, Konstantinos. Ethics in educational technology research: Informing participants on data sharing risks. British Journal of Educational Technology, v. 50, n. 3, p. 1019-1034, 2019.

BOOTH, Tony, \& AINSCOW, Mel. Index for INCLUSION: Developing Learning and Participation in Schools. Bristol: Centre for Studies on Inclusive Education, 2002.

CORRÊA, Ivete, NUNES, Suzana, \& DIAS-TRINDADE, Sara. Uma análise do nível de proficiência digital de professores do ensino médio de escolas públicas estaduais de Palmas - TO. Revista 
Observatório. v. 6, n. 1, p. 1-24, janeiro-março, 2020. DOI: http://dx.doi.org/10.20873/uft.24474266.2020v6n1a10pt.

CRESWELL, John W. Projeto de pesquisa: métodos qualitativo, quantitativo e misto. Porto Alegre: Artmed, 2007.

DIAS-TRINDADE, Sara, \& FERREIRA, António Gomes. Digital teaching skills: DigCompEdu CheckIn as an evolution process from literacy to digital fluency. ICONO14, v. 18, n. 2, p. 162-187, 2020. DOI: http://dx.doi.org/10.7195/ri14.v18i1.1519.

DIAS-TRINDADE, Sara, \& MOREIRA, José António. Assessment of high school teachers on their digital competences. MAGIS, Revista Internacional de Investigación en Educación, v. 13, p. 1-21, 2020. DOI: http://dx.doi.org/10.11144/Javeriana.m13.ahst.

DIAS-TRINDADE, Sara, MOREIRA, José António, \& NUNES, Catarina. Escala de autoavaliação de competências digitais de professores. Procedimentos de construção e validação. Texto Livre, v. 12, n. 2, p. 152-171, mai.-ago, 2019. DOI: http://dx.doi.org/10.17851/1983-3652.12.2.152-171.

DUFOUR, Richard, DUFOUR, Rebecca, EAKER, Robert, \& MANY, Thomas. Learning by Doing. A Handbook for Professional Learning Communities at Work. Bloomington: Solution Tree Press, 2016.

FIGUEIREDO, António Dias. O caminho nunca dantes percorrido. [weblog post] 27 de março 2020. Disponível em: http://adfig.com/pt/?p=476>. Acesso em: 8 set.2020.

FLORIDI, Luciano (Ed.). The Onlife Manifesto: Being Human in a Hyperconnected Era. 1. ed. s. I.: Springer Open, 2015.

HELSPER, Ellen Johanna, \& ENYON, Rebecca. Digital Natives: where is the evidence?. British Educational Research Journal, v. 3, p. 503-520, june, 2010.

HODGES, Charles, MOORE, Stephanie, LOCKEE, Barb, TORREY, Trust, \& BOND, Aaron. (2020). The difference between emergency remote teaching and online learning. Disponível em: https://er.educause.edu/articles/2020/3/the-difference-between-emergency-remote-teachingand-online-learning. Acesso em: 12 abril. 2020.

KNOX, Jeremy. Artificial Intelligence and Education in China. Learning, Media and Technology, v. 45, n. 3, p. 298-311, 2020. DOI: http://dx.doi.org/10.1080/17439884.2020.1754236.

LINDER, Christian, \& FARAHBAKHSH, Siavash. Unfolding the Black Box of Questionable Research Practices: Where Is the Line Between Acceptable and Unacceptable Practices? Business Ethics Quarterly, v. 30, n. 3, p. 335-360, 2020. DOI: http://dx.doi.org/10.1017/beq.2019.52.

MAINARDES, Jefferson, \& CARVALHO, Isabel Cristina de Moura. Autodeclaração de princípios e de procedimentos éticos na pesquisa em Educação. In ANPEd - Associação Nacional de PósGraduação e Pesquisa em Educação. Ética e Pesquisa em Educação. Subsídios. v. 1, p. 129-132, Brasil: ANPEd, 2019.

MASSANO, Lúcia, \& HENRIQUES, Susana. Liderança Digital: a aprendizagem e os processos de informação e comunicação na sala de aula, In GRAVE, Lídia, OLIVEIRA, Isolina, \& BASTOS, Glória 
(Coords.). Lideranças e Inovação em Contextos Educativos. 1. ed. Lisboa: Universidade Aberta, 2018. p. 218-234.

MEANS, Barbara, BAKIA, Marianne, \& MURPHY, Robert. Learning Online: What Research Tells Us about Whether, When and How. 1. ed. New York: Routledge, 2014.

MOREIRA, José António, HENRIQUES, Susana, \& BARROS, Daniela. Transitando de um ensino remoto emergencial para uma educação digital em rede, em tempos de pandemia. Dialogia, v. 34, p. 351-364, 2020. DOI: http://dx.doi.org/10.5585/Dialogia.N34.17123.

PARASKEVA, J. M. "Brutti, Sporchi \& Cattivi": Towards a Non-Abyssal Curriculum. Revista Tempos e Espaços em Educação, v. 9, n. 18, p. 75-90, 10 abr. 2016.

PORTUGAL. MINISTÉRIO DA EDUCAÇÃO (2020). Roteiro: 8 Princípios orientadores para a implementação do ensino a distância (E@D) nas escolas. 2020. Disponível em:

https://www.dge.mec.pt/sites/default/files/roteiro ead vfinal.pdf. Acesso em: 10 set. 2020.

REIMERS, Fernando, \& SCHLEICHER, Andreas. A framework to guide an education response to the COVID-19 Pandemic of 2020. 1. ed. s.I.: OECD, 2020.

SANGRÀ, Albert. Acesso à Internet: um direito universal. 30 de maio de 2020. [weblog post] Disponível em: https://eagoraead.wixsite.com/ensinaradistancia/post/acesso-\%C3\%A0-internetum-direito-universal. Acesso em: 8 set.2020.

SANTO, Eniel Espírito, \& DIAS-TRINDADE, Sara. Educação a Distância e Educação Remota Emergencial: aproximações e distanciamentos. In MACHADO, Dinamara (Org.). Educação em tempos de COVID-19: reflexões e narrativas de pais e professores. 1. ed. Curitiba: Editora Dialética e Realidade, 2020. p. 141-151.

SANZ, Ismael, GONZÁLEZ, Jorge Sáinz, \& CAPILLA, Ana. Efeitos da crise do COVID-19 na educação. 1. ed. Madrid: Organización de Estados Iberoamericanos para la Educación, la Ciencia y la Cultura (OEI), 2020.

SPCE - Sociedade Portuguesa de Ciências da Educação. Carta Ética. Instrumento de regulação ético-deontológica. Porto: SPCE.

STOLL, Louise. Creating capacity for learning: Are we there yet? Journal of Educational Change, v. 21, p. 421-430, 2020. DOI: http://dx.doi.org/10.1007/s10833-020-09394-z.

TOMAZINHO, Paulo. Ensino Remoto Emergencial: a oportunidade da escola criar, experimentar, inovar e se reinventar. 1. ed. Porto Alegre: SINEPE/RS, Sindicato do Ensino Privado do Rio Grande do Sul, 2020. Disponível em: https://bit.ly/2YkZrqx. Acesso em: 10 set. 2020.

WILLIAMSON, Ben, EYNON, Rebecca, \& POTTER, John. Pandemic politics, pedagogies and practices: digital technologies and distance education during the coronavirus emergency, Learning, Media and Technology, v. 45, n. 2, p. 107-114, 2020. DOI:

http://dx.doi.org/10.1080/17439884.2020.1761641.

WEF. WORLD ECONOMIC FORUM. New Vision for Education: Unlocking the Potential of Technology. 1. ed. Cologny/Geneva: World Economic Forum, 2015. 


\section{SOBRE AS AUTORAS}

\section{Sara Dias-Trindade}

Doutora em História, Didática da História e Pós-doutora em Tecnologias da Educação e da Comunicação, Universidade de Coimbra (UC); Professora na Faculdade de Letras (DHEEAA) da Universidade de Coimbra Portugal; Centro de Estudos Interdisciplinares do Século XX da Universidade de Coimbra; Grupo Humanidades Digitais.

E-mail: sara.trindade@uc.pt

ORCID: http://orcid.org/0000-0002-5927-3957

\section{Joana Duarte Correia}

Doutoranda em Sociologia, Iscte - Instituto Universitário de Lisboa; Assistente convidada no Laboratório de Competências Transversais do Iscte - Instituto Universitário de Lisboa - Portugal; Centro de Investigação e Estudos de Sociologia (CIES-Iscte).

E-mail: Joana Telma Correia@iscte-iul.pt

ORCID: http://orcid.org/0000-0002-0820-7562

\section{Susana Henriques}

Doutora em Sociologia, especialidade em Educação, Comunicação e Cultura, Iscte - Instituto Universitário de Lisboa (Iscte-IUL); Professora no Departamento de Educação e Ensino a Distância (DEED) da Universidade Aberta - Portugal; Iscte - Instituto Universitário de Lisboa / Centro de Investigação e Estudos de Sociologia (CIES-Iscte).

E-mail: Susana.Henriques@uab.pt

ORCID: https://orcid.org/0000-0002-7506-1401 